\title{
SECONDARY CAPITAL MARKETS, LONG-RUN GROWTH, AND THE TERM STRUCTURE OF ASSET YIELDS*
}

\author{
By Valerie R. Bencivenga, Bruce D. Smith, \\ AND ROSS M. STARR ${ }^{1}$ \\ University of Texas at Austin, U.S.A. \\ Federal Reserve Bank of Cleveland, U.S.A. \\ University of California, San Diego, U.S.A.
}

\begin{abstract}
An endogenous growth model is presented in which production uses a vector of capital inputs. Technologies for creating capital of different types vary by gestation period and productivity. Ownership of gestating capital must be "rolled over" in secondary capital markets in which transactions are costly. We study how reductions in transactions costs affect the equilibrium growth rate, the rate of return on saving, the volume of activity in secondary capital markets, and the term structure of asset yields. We give conditions under which reductions in transactions costs result in higher or lower growth rates.
\end{abstract}

\section{INTRODUCTION}

On any business day in New York's financial markets, tens of billions of dollars worth of securities change hands. Most of this activity takes place in secondary capital markets - that is, it rearranges the ownership of existing capital rather than channeling savings into new investment. What, then, is the contribution of these markets to capital accumulation and the process of economic growth? And what are the consequences of increasing or reducing the transactions costs in secondary capital markets for capital formation, asset yields, and growth? As these markets become larger and cheaper to access, is this necessarily growth-enhancing?

Opinions on these questions have varied widely. Keynes (1936), for example, openly questioned the economic value of easily accessed equity markets. Levine and Zervos (1998), on the other hand, argue that these markets can be a powerful force in stimulating real growth. This article undertakes an examination of these issues. It proceeds from the viewpoint that secondary capital markets mediate two competing forces that affect capital investment decisions: Much of the most productive capital is long-lived relative to the holding period of a typical individual investor, and-at the same time-investors desire the ability to convert assets into consumption cheaply prior to maturity. Secondary capital markets permit the reconciliation of these two forces. In particular, the availability of capital resale markets permits

\footnotetext{
* Received May 1997; revised June 1999.

${ }^{1}$ We would like to thank Maria Candido, Jon Heaton, Ian Jewitt, two anonymous referees, and the participants of seminars at U.C. Davis, U.C. Riverside, University of Texas at Austin, and the February 1994 NBER Economic Fluctuations Conference for extremely helpful comments. The views expressed herein are those of the authors and not necessarily those of the Federal Reserve Bank of Cleveland or the Federal Reserve System.
} 
investors to base their portfolio allocations on yields alone rather than having also to be concerned with the maturity of an investment. Secondary capital markets therefore allow the economy to separate decisions on asset holding periods from decisions on asset life. Since capital invested in forms with differing times to maturity may have differing productivity as well, markets that allow capital to be allocated to maturities of highest return, independent of time to payout, may significantly affect output and output growth.

The idea that long-lived capital makes a distinctive contribution in production has a long tradition in the theory of capital and of economic development (Bohm-Bawerk, 1891; Hicks, 1969). However, the secondary markets that make investments in this type of capital possible do not operate costlessly; indeed, the resources used and the rents extracted by the financial sector are priced to the rest of the economy in the form of transactions costs, including commission charges, bid/ask spreads in securities prices, management fees, and borrowing/lending yield spreads.

This article investigates the implications of these observations. In particular, it considers the consequences of having a set of capital investments that are long-lived relative to the period over which they are held by a typical investor. Thus ownership of these assets will be transferred through a sequence of holders, and each purchaser of an asset will be concerned with its resale potential. In addition, we assume that transactions in secondary capital markets are costly. Our purpose, then, is to introduce secondary capital markets into an otherwise conventional endogenous growth model and to examine how the costs of transacting in these markets affect the balanced growth path of an economy. In particular, we consider how changes in the costs of financial market transactions affect (1) an economy's long-run rate of growth, (2) the rate of return on saving received along a balanced growth path, (3) the composition of investment, (4) the volume of secondary market activity, and (5) the term structure of asset yields. An investigation of these questions will permit us to draw some conclusions about the connections between an economy's financial market performance and its growth performance.

In order to pursue these issues, our formal analysis must incorporate two elements. First, there must exist an array of capital investments that can be ranked by maturity (time to payout), and second, there must be transactions costs in secondary capital markets. To incorporate these features, we begin with an endogenous growth version of Diamond's (1965) neoclassical growth model. Allowing assets to have different maturities, productivities, and transactions costs is then accomplished as follows: Diamond posits that one unit of consumption foregone today becomes one unit of capital in one period. We, on the other hand, assume the existence of several technologies for converting current consumption into future capital. These technologies differ by gestation period (the time from investment to the receipt of capital $)^{2}$ and the amount and type of capital received. Capital

\footnotetext{
${ }^{2}$ The importance of lengthy gestation for capital investments is often emphasized in the development literature. See, for instance, Taylor (1980), van Wijnbergen (1982), and Buffie (1984). It also has received emphasis in the macroeconomics literature (Kydland and Prescott, 1982) and in classical writings about capital theory and growth (Bohm-Bawerk, 1891; Hicks, 1969). While, in keeping with this literature, we focus here on investments with differing gestation periods, our results also can be obtained in a model where all types of capital have the same (short) gestation period but have different productive lifetimes. We expand on this point below.
} 
produced by each technology represents a distinct argument of a standard neoclassical production function; we focus here on the case in which different types of capital are not perfectly substitutable in production. Second, we assume that transactions transferring the ownership of long-lived capital are costly and that these costs are most significant (over the life of an asset) for assets of longest maturities. ${ }^{3}$ We then investigate the consequences that the size of these transactions costs ${ }^{4}$ have for the growth rate of real activity, for the volume of financial market activity, and for asset prices and asset yields.

Finally, it deserves emphasis that we focus on the economic role of secondary capital markets (or capital resale markets) along these dimensions. It is these markets whose role in the process of growth and development has been actively debated [again, see Keynes (1936) or Levine and Zervos (1998)]. Thus we consider only transactions costs and the volume of activity in markets where claims to existing assets are traded. We do not directly analyze the placement of new issues of equity claims.

The results we obtain are as follows: A reduction in transactions costs in secondary capital markets necessarily raises the equilibrium rate of return on savings. Reductions in transactions costs, ceteris paribus, also favor the holding of long- relative to short-gestation (maturity) capital. An immediate consequence is that declining transactions costs also necessarily result in a larger volume of secondary capital market activity, since longer-gestation capital must be resold more times than shorter-gestation capital. However, the consequences of lower transactions costs for the equilibrium rate of growth are ambiguous and depend on the relative strengths of three competing forces.

First, since a decline in transactions costs does raise the rate of return on savings, it may tend to increase the economy's savings rate. If this occurs, it is conducive to growth. Second, a decline in transactions costs reduces the resource loss associated with the transfer of assets; this too is conducive to growth. However, by causing the economy to substitute toward more transactions-intensive investments lower transactions costs lead to more activity in capital resale markets. This diverts the savings of

\footnotetext{
${ }^{3}$ The reason why transactions costs are skewed by maturity is relevant to, but beyond the scope of, the present essay. The risks to market makers may be greater, or valuing assets and matching buyers with sellers may be more difficult, for assets whose payout is in the far distant future (Stoll, 1978). The notion that transactions costs are higher for assets of long maturity has a significant empirical basis. For instance, referring to the Wall Street Journal of July 23, 1993, the bid/ask spread on a 3-month Treasury bill of the previous day was 0.005 percent of the price. The bid/ask spread on a 30-year Treasury bond was 0.062 percent of the price, and the bid/ask spread on a 30-year Treasury strip (a pure discount instrument, equivalent to a long-term bill) was 0.7 percent of the price. Thus these bid/ask spreads vary by a factor of 100 with maturity alone. This effect is, of course, compounded as a longer-term instrument is rolled over many more times in its lifetime. See Sharpe (1985) for a discussion of transactions costs in equity (capital resale) markets.

${ }^{4}$ Reductions in transactions costs could occur either because the "technology of transacting" improves or because agents devise improvements in the organizational structure of these markets. A natural extension of our analysis would be to consider the level of transactions costs as endogenous. In actual securities markets, for example, the bid/ask spread is set (competitively or monopolistically) by market makers and/or specialists in the securities. The spread could then reflect the market makers' costs and attitudes toward risk. Indeed, it appears that some of the risk in asset prices is reflected in the bid/ask spread, and the spread is then incorporated in the equilibrium asset yield (Shen, 1993; Shen and Starr, 1998). However, we abstract from these issues here.
} 
young agents away from the initiation of new capital investments and into the purchase (from old agents) of already existing assets. ${ }^{5}$ The diversion of savings into secondary capital markets is detrimental to growth, and the magnitude of this diversion determines whether or not the increased liquidity of the financial system leads to an increase or a decrease in the rate of real growth.

When can the third effect dominate the other two so that reductions in transactions costs adversely affect growth? Loosely speaking, the answer is that when savings behavior is relatively interest-inelastic, and when capital of different maturities is relatively highly substitutable in production, the diversion of savings away from new capital investment and into the purchase of existing assets will cause the growth rate to fall as transactions costs are reduced. On the other hand, if the substitution possibilities between short- and long-gestation capital are relatively limited, transactions cost reductions will imply only small reallocations of investment and a small diversion of savings. It is in this situation that transactions cost reductions are most likely to be growth-enhancing.

Since the analysis allows assets of various maturities to be held simultaneously, the model also generates an equilibrium term structure of asset yields (gross of transactions costs). The term structure here is based on the transactions cost structure in the financial sector rather than, as is typical in the literature, ${ }^{6}$ on investor expectations and portfolio preferences. A law of one price prevails in asset markets: All investment instruments must generate the same rate of return, net of transaction costs. Rates of return gross of transactions costs on assets of different maturities differ by a compensating differential reflecting transactions cost differences. We take transactions costs to be largest for long-lived assets (see footnote 3), which require the highest returns (gross of transactions costs) in order to be held. The result is a familiar upward-sloping yield curve (gross of transactions costs).

Our interest in many of the issues just raised derives, in part, from the attention they receive in the development literature. Many economies have substantially less well developed secondary capital markets than the United States, and traders face much higher transactions costs. Development economists often argue ${ }^{7}$ that the high costs of financial market activity in most developing countries are a major impediment to capital accumulation and growth. The present model can be interpreted as an investigation of this view. Reductions in transactions costs can be regarded as a consequence of liberalizations and/or technical improvements in the financial sector. Our results then indicate the effects of financial deepening for capital accumulation, growth, and equilibrium rates of return.

\footnotetext{
${ }^{5}$ In effect, lower transactions costs potentially have two effects on the aggregate savings rate. First, by increasing the rate of return on savings, a reduction in transactions costs may increase the savings of young agents. Second, a reduction in transactions costs can increase the trading of claims to existing assets and thereby reduce the initiation of new investments. We expand on these points in Section 5.

${ }^{6}$ See Shiller (1990) for an overview and a bibliography.

${ }^{7}$ The original statements of this view appear in Gurley and Shaw (1967), Shaw (1973), North (1990), and McKinnon (1973); see Fry (1988) for an overview. Recent formalizations of their arguments appear in Starr (1987), Greenwood and Jovanovic (1990), Bencivenga and Smith (1991), and Greenwood and Smith (1997). See Levine and Zervos (1998) for some empirical evidence.
} 
Interpreted in this way, the possibility that a reduction in transactions costs can result in an increase in financial market size and, at the same time, can be detrimental to growth is more than simply a theoretical curiosity. A number of authors have noted that many attempts to stimulate financial market activity in developing countries by reducing the perceived costs of transacting in them have been counterproductive. ${ }^{8}$ We identify technical conditions under which this is possible, as well as conditions under which it is not.

The remainder of the article proceeds as follows: Section 2 describes the model economy, while Section 3 defines a balanced growth path equilibrium. Section 4 examines the behavior of financial markets. Section 5 provides an analysis of the consequences of changes in the transactions cost structure. Section 6 discusses the term structure of asset yields, and Section 7 concludes.

\section{THE MODEL}

2.1. Environment. We consider a version of Diamond's (1965) overlapping generations model with production, modified to allow for endogenous growth in the manner described by Shell (1966) and Romer (1986). In particular, our economy consists of an infinite sequence of identical, two-period lived, overlapping generations. In each period a single final good is produced using capital and labor as inputs.

Let $t=1,2, \ldots$ index time. At each date $t$ a new generation is born with $N>1$ identical members.' These agents are endowed with one unit of labor when young, which is supplied inelastically. Agents are then retired when old. In addition, young agents at each date have no endowment of anything other than their labor.

Let $c_{i t} \in R_{+}$denote the age $i$ consumption of a representative member of the generation born at $t$. Each member of this generation has the homothetic utility function

$$
u\left(c_{1 t}, c_{2 t}\right)=\frac{\delta c_{1 t}^{1-\eta}}{1-\eta}+\frac{c_{2 t}^{1-\eta}}{1-\eta}
$$

with $\eta \in(0,1]$.

The single final good is produced each period using a composite capital stock and labor. In addition, production is subject to the kind of externality described by Shell (1966) and Romer (1986). In particular, if $K_{t}$ is the (composite) capital stock employed by an individual producer at $t$, if $L_{t}$ is that producer's labor input at the same date, and if $\bar{k}_{t}$ is the "average" per worker capital stock, then the firm's final

\footnotetext{
${ }^{8}$ See, for instance, Taylor (1980), van Wijnbergen (1983, 1985), and Diaz-Alejandro (1985).

${ }^{9}$ It is not difficult to allow for intragenerational heterogeneity or for population growth. However, since the addition of these features adds no substantive issues to the analysis, we abstract from them here.
} 
output is given by the production function ${ }^{10}$

$$
F\left(\bar{k}_{t}, K_{t}, L_{t}\right)=A \bar{k}_{t}^{1-\beta} K_{t}^{\beta} L_{t}^{1-\beta}
$$

with $\beta \in(0,1)$.

On the production side, our analysis differs from more conventional formulations in that we assume the existence of $J>1$ different technologies for converting the final good at date $t$ into future capital. We index these technologies by $j=1, \ldots, J$; technologies differ as follows: One unit of the final good invested in technology $j$ at $t$ produces $R_{j}>0$ units of capital at time $t+j$, gross of (i.e., not accounting for) transactions costs. Thus capital production technologies are linear (as in Diamond, $1965)$ and vary by productivity $\left(R_{j}\right)$ and gestation period $(j)$. At each date there may be capital available from each of the $J$ different technologies. We assume that different types of capital produced via different investment technologies are imperfectly substitutable, entering distinctly into the production process. For simplicity, we aggregate these different types of capital as follows. Let $K_{j t}$ denote the amount of capital produced using technology $j$ that is available at $t$. Then the composite capital input is given by the CES aggregator function

$$
K_{t}=\left(\sum_{j=1}^{J} a_{j} K_{j t}^{\rho}\right)^{1 / \rho}
$$

with $a_{j}>0$ and $\rho \in[0,1) .{ }^{11}$ Finally, we assume that capital is used in production and then depreciates completely.

Notice that a unit of the final good invested in technology $j$ at $t$ is unproductive until it matures at $t+j$. Thus the capital production technology is "Austrian" in character. Of course, this formulation implies that most types of capital have gestation periods that are long relative to agents' lifetimes. Naturally, this assumption is not intended to be taken literally; it is simply a device for generating the sale of claims to existing capital assets. We could as an alternative modify the analysis in the following way: One could imagine that all capital investments mature in one period and that capital produced by different technologies has different productive lifetimes. This would lead to an economy where different capital production technologies generate distinct payoff vectors, as opposed to our "point input-point output" formulation. Such a modification of the analysis would allow us to produce

\footnotetext{
${ }^{10}$ We thus generate endogenous growth by assuming an externality associated with capital accumulation. Many other endogenous growth formulations will, of course, give rise to the same results we describe here. For example, in Bencivenga et al. (1995) we used a model where final goods are produced using a set of differentiated intermediate inputs and where there are increasing returns associated with the production of intermediate inputs. We could equally well have employed that formulation here. However, since our focus is on the consequences of transactions costs in financial markets for growth, we have opted to use the simplest possible model that delivers endogenous growth in this framework. We also note that analogous results can be obtained for steady-state equilibria in versions of this model that do not allow for sustained growth. On the latter point, see Bencivenga et al. (1994).

${ }^{11}$ The case $\rho=1$ is considered by Bencivenga et al. $(1995,1996)$. The case where the different capital inputs are perfect substitutes introduces a number of complications that are avoided when $\rho<1$.
} 
results very similar to those obtained here but at the cost of considerable additional complexity. We therefore retain the simpler "Austrian" specification. Finally, we note that differences in gestation periods have several familiar interpretations. For instance, lengthy gestation projects may require more extensive research and development, or they may simply involve longer "time to build."

Since agents are two-period lived, the use of capital production technologies with $j>1$ requires agents to sell capital goods in process (CIP) in capital resale markets. ${ }^{12}$ In particular, capital investments in technologies with $j>1$ are unproductive until they mature, so these investments are "rolled over" by investors in secondary capital markets from inception to maturity. We focus on how the costs of transacting in these markets affects the level of both real and financial market activity.

For simplicity, we assume a proportional transactions cost structure. When one unit of technology $j$ CIP is sold $h$ periods after initiation (so that the CIP is $j-h$ periods from maturity), the fraction $\alpha^{j, h} \in[0,1)$ of the capital is lost. We assume that there are no transactions costs associated with renting capital or labor or with initiating the capital investment. ${ }^{13}$

2.2. Trade. At each date there is a set of firms that rent labor and (ready-touse/mature) capital from households in competitive factor markets. Let $K_{j t}$ denote that quantity of (mature) type $j$ capital rented by a typical firm at $t$, and let $L_{t}$ denote the firm's labor input. Let $r_{j t}$ denote the real rental rate on type $j$ capital at the same date, and let $w_{t}$ denote the real wage. Then a typical firm chooses a value $L_{t}$ and a $J$-vector $\left(K_{1 t}, K_{2 t}, \ldots, K_{J t}\right)$ to solve the problem

$$
\max F\left[\vec{k}_{t},\left(\sum_{j} a_{j} K_{j t}^{\rho}\right)^{1 / \rho}, L_{t}\right]-w_{t} L_{t}-\sum_{j} r_{j t} K_{j t}
$$

taking $\bar{k}_{t}$ as given. Letting $k_{j t} \equiv K_{j t} / L_{t}$ and

$$
k_{t} \equiv \frac{K_{t}}{L_{t}} \equiv \frac{\left(\sum_{j} a_{j} K_{j t}^{\rho}\right)^{1 / \rho}}{L_{t}} \equiv\left(\sum_{j} a_{j} k_{j t}^{\rho}\right)^{1 / \rho}
$$

\footnotetext{
${ }^{12}$ Of course, this also would be the case if all capital investments matured in one period, but some types of capital had a long productive lifetime.

${ }^{13}$ This assumption keeps the formulation as close as possible to the Diamond (1965) model and emphasizes our focus on transactions costs in secondary capital markets. Parenthetically, our analysis is agnostic as to whether agents trade claims to CIP individually or through intermediaries such as mutual funds. In particular, if CIP is held through a mutual fund, the overlapping generations structure of our model implies that mutual fund shares would have to be traded. We adopt the natural view that trading shares in mutual funds is the same as trading claims to the funds' underlying assets. Thus whether asset trading is intermediated or not has no implications here. See Aiyagari and Gertler (1991) for a discussion of transactions costs associated with trading and/or liquidating mutual fund shares.
} 
denote the appropriate capital-labor ratios, the first-order conditions for the problem (P.1) can then be written in the form

$$
\begin{gathered}
a_{j} \beta A \bar{k}_{t}^{1-\beta} k_{t}^{\beta-1}\left(\frac{k_{t}}{k_{j t}}\right)^{1-\rho}=r_{j t} \\
(1-\beta) A \bar{k}_{t}^{1-\beta} k_{t}^{\beta}=w_{t}
\end{gathered}
$$

Imposing the obvious equilibrium condition $\bar{k}_{t}=k_{t}$ in Equations (3) and (4), we then obtain the following factor pricing relationships:

$$
\begin{gathered}
a_{j} \beta A\left(\frac{k_{t}}{k_{j t}}\right)^{1-\rho}=r_{j t} \\
(1-\beta) A k_{t}=w_{t}
\end{gathered}
$$

On the household side, each young individual earns the real wage $w_{t}$ at $t$. Given this young period income level, households choose a savings level and make decisions about how to allocate their portfolios among different available capital investments. In particular, household savings can be used either to initiate new capital investments or to purchase existing CIP that has yet to mature. Let $S_{t}^{j, h}$ be the amount of type $j \mathrm{CIP}^{14}$ that is $h$ periods old ( $j-h$ periods from maturity) that is purchased by a representative household at $t$. Further, let $P_{t}^{j, h}$ denote the price (in units of current consumption) of one unit of technology $j$ CIP $h$ periods after initiation. Since, by choice of units, one unit of current consumption invested in technology $j$ initiates one unit of technology $j$ CIP, $P_{i}^{j, 0}=1$. Also, one unit of mature technology $j$ CIP yields $R_{j}$ units of rentable type $j$ capital. Thus the market value of one unit of mature CIP is simply its rental value; that is, $P_{t}^{j, j}=R_{j} r_{j t}$. For $j>1$ and $0<h<j, P_{i}^{j, h}$ will have to be determined.

Without loss of generality, we can adopt the convention that transactions costs are born by sellers of CIP. Thus a representative young agent chooses a vector of consumption levels $\left(c_{1 t}, c_{2 t}\right)$ and a matrix of capital investment choices $\left(S_{t}^{j, h}\right)$ to maximize $u\left(c_{1 t}, c_{2 t}\right)$ subject to

$$
\begin{gathered}
c_{1 t} \leq w_{t}-\sum_{j=1}^{J} \sum_{h=0}^{j-1} P_{t}^{j, h} S_{t}^{j, h} \\
c_{2 t} \leq \sum_{j=1}^{J} \sum_{h=0}^{j-1} P_{i+1}^{j, h+1} S_{i}^{j, h}\left(1-\alpha^{j, h+1}\right)
\end{gathered}
$$

and nonnegativity.

It should be evident from Equation (5) that $k_{j t}>0$ for all $j$ must hold along any nontrivial balanced growth path. Thus each technology must be in use at each date, and type $j$ CIP must be held by some young agent for all possible times to maturity. Then, at each date, some young agent has $S_{t}^{j, h}>0$ for all $j$, for all $h=0,1, \ldots, j-1$.

\footnotetext{
${ }^{14}$ Recall that one unit of consumption foregone and invested becomes one unit of CIP.
} 
This clearly requires that the net of transactions costs rate of return on all possible investments be equated; that is,

$$
\left(1-\alpha^{j, h+1}\right) \frac{P_{t+1}^{j, h+1}}{P_{t}^{j, h}}=\left(1-\alpha^{l, m+1}\right) \frac{P_{t+1}^{l, m+1}}{P_{t}^{l, m}}
$$

must hold for all $h$ and $m$ satisfying $h \leq j-1$ and $m \leq l-1$ and for all values $j$ and $l$. Notice in particular that all possible investments bear a common net of transactions costs rate of return, which we denote by $\gamma_{t} \cdot \gamma_{t}$ satisfies

$$
\gamma_{t}=\left(1-\alpha^{j, h+1}\right) \frac{P_{t+1}^{j, h+1}}{P_{t}^{j, h}}
$$

for all $j$, for all $h=0,1, \ldots, j-1$.

Equation (10) implies that each young agent is individually indifferent regarding his or her portfolio composition. ${ }^{15}$ For young agents, then, only the real value of savings, denoted by $\tilde{S}_{t} \equiv \sum_{j} \sum_{h} P_{t}^{j, h} S_{t}^{j, h}$, is determinate. It is easy to verify that this value is given by the expression

$$
\tilde{S}_{t}=\Phi\left(\gamma_{t}\right) w_{t}
$$

where

$$
\Phi\left(\gamma_{t}\right) \equiv \frac{\delta^{\frac{-1}{\eta}} \gamma^{\frac{1-\eta}{\eta}}}{1+\delta^{\frac{-1}{\eta}} \gamma^{\frac{1-\eta}{\eta}}}
$$

The assumption $\eta \leq 1$ that implies that $\Phi^{\prime}(\gamma) \geq 0$ holds. Thus savings is nondecreasing in the real rate of return $\gamma$.

For future reference, it will be useful to have a notation for the fraction of savings -in real terms - that is held in type $j$ CIP that is $h$ periods old. Let $\theta_{t}^{j, h}$ denote the value of this fraction at $t$. Then, in per capita terms,

$$
\theta_{t}^{j, h}=\frac{P_{t}^{j, h} S_{t}^{j, h}}{\tilde{S}_{t}}
$$

Clearly, then

$$
\sum_{j=1}^{J} \sum_{h=0}^{j-1} \theta_{t}^{j, h}=1
$$

must hold.

\footnotetext{
${ }^{15}$ In the aggregate, the fraction of savings invested in each technology and each time to maturity will be determinate, however.
} 


\section{BALANCED GROWTH PATHS}

For the remainder of this article we focus on equilibria displaying balanced growth paths. Thus, in particular, we focus on equilibria in which

$$
k_{t+1}=\sigma k_{t}
$$

so that $\sigma$ is the endogenously determined gross rate of real growth in the (per capita) capital stock. Along a balanced growth path, $\gamma_{t}$ also will be constant, and we henceforth omit time subscripts on $\gamma$.

In order to ease the exposition of the general case, we begin by describing the determination of a balanced growth path when there is only a single capital production technology $(J=1)$.

3.1. The Case $J=1$. When $J=1$, Equation (10) implies that $\gamma=P_{t+1}^{1,1} / P_{t}^{1,0}=$ $R_{1} r_{1 t} \cdot{ }^{16}$ Moreover, in this case, $k_{t}=k_{1 t}$ and $a_{1}=1$, so that from Equation (5), $r_{1 t}=\beta A$. It follows that the gross rate of return satisfies $\gamma=R_{1} \beta A$. Note, in particular, that the rate of return can be determined independently of the rate of growth. This is a consequence of introducing the Romer (1986) endogenous growth formulation into the Diamond (1965) model.

In addition, when $J=1$, there is no resale market for CIP. Hence all savings are used to initiate new capital investments. It follows that

$$
k_{t+1}=R_{1} \Phi(\gamma) w_{t}=R_{1} \Phi(\gamma)(1-\beta) A k_{t}
$$

Thus the gross rate of growth is given by

$$
\sigma=\frac{k_{t+1}}{k_{t}}=R_{1} \Phi(\gamma)(1-\beta) A \equiv R_{1} \Phi\left(R_{1} \beta A\right)(1-\beta) A
$$

The recursive structure of this endogenous growth version of the Diamond model essentially will be preserved in the more complicated case $J>1$.

Finally, for future reference, we observe that $\left(\partial \sigma / \partial R_{1}\right)\left(R_{1} / \sigma\right)=1+$ $\gamma \Phi^{\prime}(\gamma) / \Phi(\gamma) \geq 1$. In particular, an increase in the productivity of the capital production technology must be growth enhancing when $J=1$ and $\Phi^{\prime}(\gamma) \geq 0$. This will not be true when $J>1$. We now turn to a consideration of this case.

3.2. The General Case $(J \geq 2)$. In order to characterize a constant growth rate equilibrium when $J \geq 2$, we begin by recalling that $P_{t}^{j, 0}=1$ and $P_{t}^{j, j}=R_{j} r_{j t}$ hold for all $j$. In addition, we note that

$$
P_{t}^{j, j} \equiv \frac{P_{t}^{j, j}}{P_{t-1}^{j, j-1}} \frac{P_{t-1}^{j, j-1}}{P_{t-2}^{j, j-2}} \cdots \frac{P_{t-j+1}^{j, 1}}{P_{t-j}^{j, 0}} P_{t-j}^{j, 0}=\frac{(\gamma)^{j}}{\prod_{h=0}^{j-1}\left(1-\alpha^{j, h+1}\right)}
$$

where $(\gamma)^{j}$ denotes the $j$ th power of $\gamma$ and where the second inequality in Equation (12) follows from Equation (10). Substituting $P_{t}^{j, j}=R_{j} r_{j t}$ into Equation (12) and

\footnotetext{
${ }^{16}$ When $J=1$, there is no resale of claims to existing capital, and hence no transactions costs are incurred.
} 
defining

$$
\tilde{R}_{j}=R_{j} \prod_{h=0}^{j-1}\left(1-\alpha^{j, h+1}\right)
$$

to be the net of transactions costs productivity of technology $j$, we then have that

$$
r_{j t}=\frac{(\gamma)^{j}}{\tilde{R}_{j}} \quad j=1, \ldots, J
$$

Thus the rental rate of each type of capital is necessarily constant along a balanced growth path. Moreover, Equations (5) and (14) imply that along such a path,

$$
k_{j t}=k_{t}\left[\frac{a_{j} \tilde{R}_{j} \beta A}{(\gamma)^{j}}\right]^{1 / 1-\rho}
$$

holds for all $j=1, \ldots, J$. Thus the composition of the capital stock is constant as well.

Equation (15) gives the composition of the composite capital stock-i.e., the terms $k_{j t} / k_{t}$ as functions of the discounted present value of investment in new technology $j$ capital. In particular, one unit invested in technology $j$ today yields $\tilde{R}_{j}$ units of type $j$ capital (net of transactions costs) in $j$ periods. This capital has a marginal product of $a_{j} \beta A j$ periods hence or, in other words, a marginal product of $a_{j} \beta A /(\gamma)^{j}$ when discounted to the present. Notice that $k_{j t} / k_{t}$ is an increasing function of this discounted present value of marginal product.

We now use Equation (2) - the definition of the aggregate capital stock - and Equation (15) to observe that

$$
k_{t}^{\rho}=\sum_{j} a_{j} k_{j t}^{\rho}=k_{t}^{\rho} \sum_{j} a_{j}\left[\frac{a_{j} \tilde{R}_{j} \beta A}{(\gamma)^{j}}\right]^{\rho / 1-\rho}
$$

Therefore, in equilibrium

$$
\sum_{j=1}^{J} a_{j}\left[\frac{a_{j} \tilde{R}_{j} \beta A}{(\gamma)^{j}}\right]^{\rho / 1-\rho}=1
$$

must hold. Equation (16) describes a condition that must be satisfied by the discounted present values of investments in the various capital production technologies in order for there to be no "arbitrage" opportunities confronting investors. In order to see this, note that Equation (16) is equivalent to

$$
\beta A=\sum_{j=1}^{J}\left[\frac{a_{j} \tilde{R}_{j} \beta A}{(\gamma)^{j}}\right]^{1 / 1-\rho}\left[\frac{(\gamma)^{j}}{\tilde{R}_{j}}\right]
$$

or to

$$
\beta A k_{t}=\sum_{j=1}^{J} \frac{k_{j t}}{\tilde{R}_{j}}(\gamma)^{j}
$$


$\beta A k_{t}$ is the rental value of $k_{t}$ units of capital at $t . k_{j t} / \tilde{R}_{j}$ is the quantity of goods required at $t-j$ to deliver $k_{j t}$ units of type $j$ capital (net of transactions costs) at $t$; $\left[k_{j t} / \tilde{R}_{j}\right](\gamma)^{j}$ is the date $t$ value of these goods.

As in the case of $J=1$, Equation (16) determines the equilibrium value of $\gamma$ independently of the values of all other endogenous variables. In particular, Equation (16) uniquely defines the equilibrium rate of return on savings $\gamma^{*}$ as a function of the net of transactions costs productivities of the various investment technologies, say

$$
\gamma^{*}=\Psi\left(\tilde{R}_{1}, \tilde{R}_{2}, \ldots, \tilde{R}_{J}\right)
$$

In addition, it is straightforward to verify that $\Psi_{j}>0$ holds, for all $j=1, \ldots, J$. Thus an increase in the net of transactions costs productivities of any capital investment technology necessarily raises the equilibrium rate of return on savings, just as in the case $J=1$.

It now remains to describe the equilibrium rate of growth of the capital stock. In order to do so, we proceed as follows: The demand at $t$ for type $j$ CIP that is $h$ periods old is simply given by $\theta^{j, h} \Phi(\gamma) w_{t} / P_{t}^{j, h} \cdot{ }^{17}$ The supply of such projects, again measured in units of CIP, equals

$$
\theta^{j, 0} \Phi(\gamma) w_{t-h} \prod_{l=0}^{h-1} \frac{\left(1-\alpha^{j, l+1}\right)}{P_{t}^{j, 0}}=\theta^{j, 0} \Phi(\gamma) w_{t-h} \prod_{l=0}^{h-1}\left(1-\alpha^{j, l+1}\right) \quad j=1, \ldots, J
$$

This expression obtains for the following reason: At $t$ the supply of $h$-period-old CIP in technology $j$ is the amount initiated at $t-h$, which along a balanced growth path is $\theta^{j, 0} \Phi(\gamma) w_{t-h} / P_{t}^{j, 0}$, less the amount consumed by transactions costs. The latter quantity - the loss due to transactions costs-is $1-\prod_{l=0}^{h-1}\left(1-\alpha^{j, l+1}\right)$ of the initial investment when it has been in place for $h$ periods.

Equality between the supply of and demand for technology $j$ CIP of vintage $h$ requires that

$$
\theta^{j, h} \Phi(\gamma) w_{t}=P_{t}^{j, h} \theta^{j, 0} \Phi(\gamma) w_{t-h} \prod_{l=0}^{h-1}\left(1-\alpha^{j, l+1}\right) \quad j=1, \ldots, J
$$

Evidently, Equation (18) reduces to

$$
\theta^{j, h}=P_{t}^{j, h} \theta^{j, 0} \frac{w_{t-h}}{w_{t}} \prod_{l=0}^{h-1}\left(1-\alpha^{j, l+1}\right)
$$

\footnotetext{
${ }^{17}$ Along a balanced growth path $\theta_{i}^{j, h}$ must be constant and hence the omission of the time subscript on $\theta^{j, h}$.
} 
We now observe that

$$
P_{t}^{j, h}=\frac{P_{t}^{j, h}}{P_{t-1}^{j, h-1}} \frac{P_{t-1}^{j, h-1}}{P_{t-2}^{j, h-2}} \cdots \frac{P_{t-h+1}^{j, 1}}{P_{t-h}^{j, 0}} P_{t-h}^{j, 0}=\frac{(\gamma)^{h}}{\prod_{l=0}^{h-1}\left(1-\alpha^{j, l+1}\right)}
$$

where the second equality follows from Equation (10). Substituting Equation (20) into Equation (19), we obtain that the market for type $(j, h)$ CIP clears at all dates along a balanced growth path iff

$$
\theta^{j, h}=\theta^{j, 0}\left(\frac{\gamma}{\sigma}\right)^{h}
$$

since $w_{t-h} / w_{t}=\sigma^{-h}$.

It is also the case, of course, that the equilibrium portfolio weights must sum to one. Therefore, Equation (21) implies that

$$
\sum_{j=1}^{J} \sum_{h=0}^{j-1} \theta^{j, h}=\sum_{j=1}^{J} \sum_{h=0}^{j-1} \theta^{j, 0}\left(\frac{\gamma}{\sigma}\right)^{h}=1
$$

Using

$$
\sum_{h=0}^{j-1}\left(\frac{\gamma}{\sigma}\right)^{h}=\frac{\left(\frac{\gamma}{\sigma}\right)^{j}-1}{\left(\frac{\gamma}{\sigma}\right)-1}
$$

in Equation (22) then yields

$$
\sum_{j=1}^{J} \theta^{j, 0}\left[\left(\frac{\gamma}{\sigma}\right)^{j}-1\right]=\left(\frac{\gamma}{\sigma}\right)-1
$$

As a final step, we note that the amount of mature type $j$ capital (per capita) at $t$ is simply the amount of type $j$ CIP initiated at $t-j$ times the (net of transactions costs) productivity of technology $j$. Thus

$$
k_{j, t+j}=\tilde{R}_{j} \theta^{j, 0} \Phi(\gamma) A(1-\beta) k_{t} \quad j=1, \ldots, J
$$

Since

$$
k_{j, t+j}=k_{t+j}\left[\frac{a_{j} \tilde{R}_{j} \beta A}{(\gamma)^{j}}\right]^{1 / 1-\rho}
$$

must hold, Equations (24) and (25) imply that

$$
\left[\frac{a_{j} \tilde{R}_{j} \beta A}{(\gamma)^{j}}\right]^{1 / 1-\rho} k_{t+j}=R_{j} \theta^{j, 0} \Phi(\gamma) A(1-\beta) k_{t} \quad j=1, \ldots, J
$$


Solving Equation (26) for $\theta^{j, 0}$ and using $k_{t+j} / k_{t}=\sigma^{j}$ along a balanced growth path, we obtain

$$
\theta^{j, 0}=\frac{a_{j}\left(\frac{\sigma}{\gamma}\right)^{j}\left[\frac{a_{j} \tilde{R}_{j} \beta A}{(\gamma)^{j}}\right]^{\rho / 1-\rho}}{(1-\beta) \Phi(\gamma) / \beta} \quad j=1, \ldots, J
$$

Equations (21) and (27) describe the equilibrium portfolio weights attached to each type of asset as a function of the equilibrium rate of growth $(\sigma)$ and rate of return to saving $(\gamma)$, as well as of the net of transactions costs productivity parameters $\left(\tilde{R}_{1}, \tilde{R}_{2}, \ldots, \tilde{R}_{J}\right)$.

Suppose we now define the functions $H_{j}: \Re_{+} \rightarrow \Re_{+}, j=1, \ldots, J$, by

$$
H_{j}(x)=\frac{x^{j}-1}{x^{j}(x-1)}
$$

Then substituting Equation (27) into Equation (23) and rearranging terms, we obtain the additional equilibrium condition

$$
\Phi(\gamma)\left(\frac{1-\beta}{\beta}\right)=\sum_{j=1}^{J} a_{j}\left[\frac{a_{j} \tilde{R}_{j} \beta A}{(\gamma)^{j}}\right]^{\rho / 1-\rho} H_{j}\left(\frac{\gamma}{\sigma}\right)
$$

Equation (29) describes a relationship that must obtain between $\gamma$ and $\sigma$ in order for savings to equal investment [as required by Equation (24)], the market for type $(j, h)$ CIP to clear for all $(j, h)$ pairs [as required by Equation (18)], and for portfolio weights to sum to one [as required by Equation (22)]. Thus Equations (16) and (29) are the conditions that determine $\gamma$ and $\sigma$ along any balanced growth path. Evidently these conditions are recursive; Equation (16) uniquely determines $\gamma$. Then substitution of Equation (17) into Equation (29) gives a relation that determines $\sigma$.

It clearly will be important to establish some properties of the functions $H_{j}$; these are summarized in the following lemma.

LEMma 1. For all $x \geq 0$, and for all $j=1, \ldots, J$, we have
(a) $H_{j}(x) \geq 0$
(b) $H_{j+1}(x) \geq H_{j}(x)$ with strict inequality for all $x<\infty$
(c) $\lim _{x \rightarrow 0} H_{j}(x)=\infty$
(d) $\lim _{x \rightarrow \infty} H_{j}(x)=0$
(e) $H_{j}^{\prime}(x)<0$

The proof of Lemma 1 appears in the Appendix.

We are now prepared to state the main result of this section. Its proof appears in the Appendix. 
Proposition 1. There exists a unique nontrivial balanced growth path. It has associated with it a unique rate of return on savings $\gamma^{*}$ described by Equation (16), while the real growth rate $\sigma^{*}$ satisfies Equation (29).

It is also straightforward to establish the following result.

Proposition 2. Suppose that $\Phi\left(\gamma^{*}\right)(1-\beta) / \beta \leq 1$ holds. Then $\gamma^{*}>\sigma^{*}$ holds.

The proof of Proposition 2 is also in the Appendix. The proposition asserts that if the equilibrium savings rate does not exceed the ratio of capital's share to labor's share, then the equilibrium (real) interest rate exceeds the rate of growth. Certainly $\Phi\left(\gamma^{*}\right) \leq \beta /(1-\beta)$ is an empirically plausible condition.

\section{FINANCIAL MARKETS}

Much of our interest centers on how changes in the level of transactions costs affect the rate of capital accumulation, the rate of return to savings, the volume of activity in secondary capital markets, and the term structure of returns. We now describe the equilibrium determination of these variables.

4.1. Transactions Volume. The real value (measured in units of current consumption) of purchases by young agents in secondary capital markets at $t$ is given by the term $\Phi(\gamma) w_{t}\left(1-\sum \theta^{j, 0}\right){ }^{18}$ In particular, young agents at $t$ have savings with a real value of $\Phi(\gamma) w_{t}$, and the fraction $\sum \theta^{j, 0}$ of this savings is invested in the initiation of new capital investment. The residual $\Phi(\gamma) w_{t}\left(1-\sum \theta^{j, 0}\right)$, goes toward the purchase of already existing CIP in capital resale markets.

Clearly, then, $1-\sum \theta^{j, 0}$ represents the fraction of wealth (savings) invested in the purchase of claims to existing capital investment at $t$. As such, $1-\sum \theta^{j, 0}$ is a measure of the volume of trading in capital resale markets (relative to assets) along a balanced growth path. ${ }^{19}$ We now characterize this volume.

Proposition 3. Along a balanced growth path,

$$
1-\sum_{j} \theta^{j, 0}=\frac{\gamma^{*}}{\sigma^{*}}-\frac{\beta}{(1-\beta) \Phi\left(\gamma^{*}\right)}
$$

Proposition 3 is proved in the Appendix. Note that the proposition asserts that the volume of secondary capital market activity is increasing in the real return on savings $\gamma^{*}$ because $\Phi^{\prime}(\gamma) \geq 0$ holds and is decreasing in the equilibrium rate of growth. The latter inverse relationship between growth and the volume of financial market activity may appear as something of a surprise. However, it has a simple interpretation. Higher levels of equity market activity, for a given value of $\gamma$, divert

\footnotetext{
${ }^{18}$ Again, recall that this refers to the volume of trade to claims in existing assets. It does not refer to the initiation of new capital investment.

${ }^{19}$ This is the measure of equity market activity employed by Levine and Zervos (1998).
} 
savings away from the initiation of new capital investment and toward the purchase of already existing capital (in process). This is analogous to a reduction in the savings rate in conventional endogenous growth models and hence is detrimental to growth, ceteris paribus. Of course this does not imply that reductions in transactions costs necessarily reduce the equilibrium rate of growth, even though-as we will show - they necessarily increase the volume of secondary capital market activity. This is so because such reductions also raise $\gamma^{*}$.

To make our point about the relationship between secondary capital market activity and aggregate savings more precise, we proceed as follows. Total per capita consumption at $t$, as a fraction of per capita output, is given by

$$
\frac{c_{1 t}+c_{2 t-1}}{Y_{t}}=\frac{[1-\Phi(\gamma)] w_{t}+\gamma \Phi(\gamma) w_{t-1}}{Y_{t}}=(1-\beta)\left[1-\Phi(\gamma)+\frac{\gamma}{\sigma} \Phi(\gamma)\right]
$$

Then the aggregate savings (new investment) rate is given by

$$
\begin{aligned}
1-(1-\beta)\left[1-\Phi(\gamma)+\frac{\gamma}{\sigma} \Phi(\gamma)\right] & =(1-\beta) \Phi(\gamma)\left[1+\frac{\beta}{(1-\beta) \Phi(\gamma)}-\frac{\gamma}{\sigma}\right] \\
& =(1-\beta) \Phi(\gamma) \sum \theta^{j, 0}
\end{aligned}
$$

Thus higher levels of equity market activity, ceteris paribus, imply a reduction in the aggregate savings rate. This, of course, is analogous to the consequences of introducing money or national debt into the conventional Diamond model.

4.2. The Term Structure of Returns. Let $\lambda_{j}$ denote the gross yield to maturity on investments in technology $j$ CIP, gross of transactions costs. Then, along a balanced growth path,

$$
\lambda_{j} \equiv\left(\frac{P^{j, j}}{P^{j, 0}}\right)^{1 / j} \equiv\left[\prod_{h=0}^{j-1} \frac{P^{j, h+1}}{P^{j, h}}\right]^{1 / j} \equiv \gamma\left[\prod_{h=0}^{j-1}\left(1-\alpha^{j, h+1}\right)\right]^{-1 / j} \equiv \gamma\left(\frac{R_{j}}{\tilde{R}_{j}}\right)^{1 / j}
$$

Thus the term structure is completely determined by the one-period (real) rate of return and the structure of transactions costs in secondary capital markets. Similarly, term premia (yield spreads between maturities) depend on these same objects.

$$
\lambda_{j}-\lambda_{j^{\prime}}=\gamma\left\{\left[\prod_{h=0}^{j-1}\left(1-\alpha^{j, h+1}\right)\right]^{-1 / j}-\left[\prod_{h=0}^{j^{\prime}-1}\left(1-\alpha^{j^{\prime}, h+1}\right)\right]^{-1 / j^{\prime}}\right\}
$$

\section{COMPARATIVE DYNAMICS}

In this section we investigate how a change in the level of transactions costs affects the equilibrium rate of return $\gamma^{*}$ and the equilibrium rate of growth $\sigma^{*}$. We first show that while a reduction in transactions costs necessarily raises the equilibrium rate of interest, such a reduction has ambiguous consequences for the growth rate of the economy. After observing why this is the case, we proceed to a more 
complete characterization of when reductions in transactions costs are and are not growth-enhancing in the case $J=2$.

5.1. The General Case. Figure 1 depicts the equilibrium loci defined by Equations (16) and (29). Evidently the locus defined by Equation (16) is vertical in the figure. Under the assumption that $\rho \geq 0$, it is easy to see that Equation (29) defines an upward-sloping locus.

The fact that $\Psi_{j}>0$ holds for all $j$ implies that a reduction in transactions costs necessarily shifts the locus defined by Equation (16) to the right in Figure 1. In particular, a reduction in one or more of the transactions cost parameters $\alpha^{j, h}$ must increase at least one of the net-of-transactions costs productivity parameters $\tilde{R}_{j}$. This, in turn, necessarily increases the (net of transactions costs) internal rate of return on at least one investment alternative. As a consequence, the rate of return on savings must increase.

In addition, it is easy to verify that $\rho \geq 0$ implies that a reduction in transactions costs (an increase in at least one of the values $\tilde{R}_{j}$ ) shifts the locus defined by Equation (29) downward in Figure 1. As a result, the equilibrium position of the economy shifts from point $A$ to point $B$, with ambiguous consequences for the equilibrium growth rate of the economy. Thus lower transactions costs can lead either to an increase or to a decrease in the rate of growth. What accounts for this ambiguity?

A reduction in transactions costs affects the equilibrium rate of growth through three channels. First, as we have seen, such a reduction necessarily raises the equilibrium rate of return on savings $\gamma^{*}$. If $\Phi^{\prime}(\gamma)>0$ holds, one implication is that the savings rate of young agents will rise. This, of course, is conducive to growth. Second, an increase in any of the values $\tilde{R}_{j}$ increases the (net of transactions costs) productivity of at least one type of capital investment. An increase in the productivity of investment is also conducive to growth.

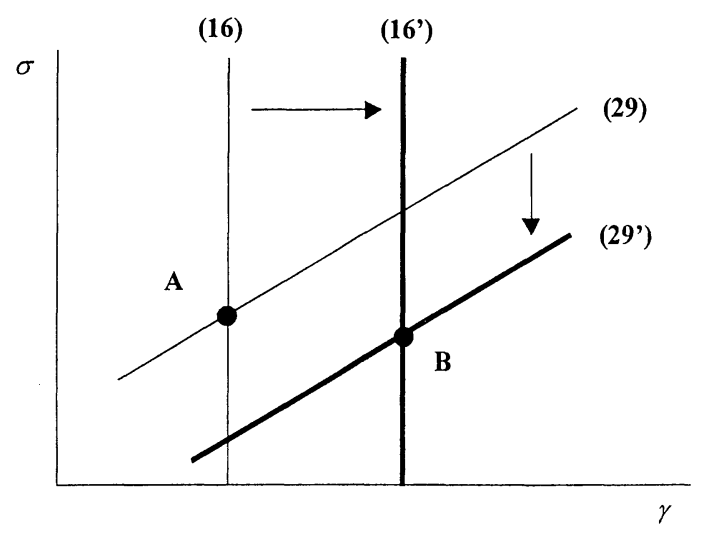

FIGURE 1

A Reduction in Transactions Costs 
However, the third effect of a reduction in transactions costs need not be conducive to growth. As demonstrated in proposition 3, an increase in $\gamma^{*}$ tends to increase the fraction of savings invested in the purchase of CIP and therefore to reduce the fraction of savings invested in the initiation of new capital investment. And, indeed, if a reduction in transactions costs reduces $\sigma^{*}$, it is apparent from our previous discussion that the fraction of total savings invested in new capital production must decline.

When will the first two effects outweigh the third? This depends on several factors, including the interest elasticity of savings and the sensitivity of the ratio $\gamma^{*} / \sigma^{*}$ to changes in transactions costs. The latter turns out to depend on the degree of substitutability between long- and short-gestation capital in production. We now wish to explore this observation further. In order to simplify the exposition, we henceforth focus on the case where there are only two capital production technologies. $^{20}$

5.2. The Case $J=2$. When $J=2$, Equation (16) reduces to

$$
a_{1}\left(\frac{a_{1} \tilde{R}_{1} \beta A}{\gamma}\right)^{\rho / 1-\rho}+a_{2}\left(\frac{a_{2} \tilde{R}_{2} \beta A}{\gamma^{2}}\right)^{\rho / 1-\rho}=1
$$

In addition, since $H_{1}(\gamma / \sigma)=\sigma / \gamma$ and $H_{2}(\gamma / \sigma)=\sigma / \gamma+(\sigma / \gamma)^{2}$, Equation (29) becomes

$$
\begin{aligned}
\Phi(\gamma) \frac{1-\beta}{\beta}= & \frac{\sigma}{\gamma}\left[a_{1}\left(\frac{a_{1} \tilde{R}_{1} \beta A}{\gamma}\right)^{\rho / 1-\rho}+a_{2}\left(\frac{a_{2} \tilde{R}_{2} \beta A}{\gamma^{2}}\right)^{\rho / 1-\rho}\right] \\
& +\left(\frac{\sigma}{\gamma}\right)^{2} a_{2}\left(\frac{a_{2} \tilde{R}_{2} \beta A}{\gamma^{2}}\right)^{\rho / 1-\rho}
\end{aligned}
$$

In view of Equation (31), Equation (32) can be rewritten as

$$
\Phi(\gamma) \frac{1-\beta}{\beta}=\frac{\sigma}{\gamma}+\left(\frac{\sigma}{\gamma}\right)^{2} a_{2}\left(\frac{a_{2} \tilde{R}_{2} \beta A}{\gamma^{2}}\right)^{\rho / 1-\rho}
$$

Since no transactions are required for one-period investments, $\tilde{R}_{1}=R_{1}$; i.e., there are no transactions costs associated with investments in technology 1 . Thus a reduction in transactions costs can be represented by an increase in the parameter $\tilde{R}_{2}$. We now consider the consequences of such an increase. For simplicity, we consider the case in which $\Phi^{\prime}(\gamma)=0$, and therefore, we henceforth simply write the

\footnotetext{
${ }^{20}$ If there are more than two capital production technologies, then in order to obtain any definitive results, it is necessary to put considerable structure on the parameters $\left(\tilde{R}_{1}, \tilde{R}_{2}, \ldots, \tilde{R}_{J}\right)$ and on how they vary with the "level" of transactions costs. See Bencivenga et al. (1994) for a discussion.
} 
savings rate as $\Phi .^{21}$ Since essentially all the existing empirical evidence suggests that the interest elasticity of savings is fairly low, this should be a reasonable assumption. However, some of our results can be overturned if the interest elasticity of savings is sufficiently large; we comment further on this possibility below.

We can now state our results about how an increase in $\tilde{R}_{2}$ affects the rate of return on savings, the level of secondary capital market activity, and the equilibrium growth rate.

Proposition 4. (a) An increase in $\tilde{R}_{2}$ has the following proportional effect on $\gamma^{*}$ :

$$
\left(\frac{\tilde{R}_{2}}{\gamma^{*}}\right) \frac{\partial \gamma^{*}}{\partial \tilde{R}_{2}}=\frac{a_{2}\left[\frac{a_{2} \tilde{R}_{2} \beta A}{\left(\gamma^{*}\right)^{2}}\right]^{\rho / 1-\rho}}{1+a_{2}\left[\frac{a_{2} \tilde{R}_{2} \beta A}{\left(\gamma^{*}\right)^{2}}\right]^{\rho / 1-\rho}}<0.5
$$

(b) If $\Phi^{\prime}(\gamma)=0$ holds, then

$$
\frac{\partial\left(\sigma^{*} / \gamma^{*}\right)}{\partial \tilde{R}_{2}}<0
$$

holds. It then follows from Equation (30) that a reduction in transactions costs raises the level of activity in capital resale markets.

(c) An increase in $\tilde{R}_{2}$ reduces the equilibrium rate of growth (i.e., $\partial \sigma^{*} / \partial \tilde{R}_{2} \leq 0$ holds) iff

$$
\left(\frac{\tilde{R}_{2}}{\gamma^{*}}\right) \frac{\partial \gamma^{*}}{\partial \tilde{R}_{2}} \leq-\left(\frac{\tilde{R}_{2}}{\sigma^{*} / \gamma^{*}}\right) \frac{\partial\left(\sigma^{*} / \gamma^{*}\right)}{\partial \tilde{R}_{2}}
$$

(d) A necessary condition for Equation (34) to hold is that

$$
\frac{\rho}{1-\rho}>\frac{1-\beta}{\beta} \Phi
$$

Sufficient conditions for Equation (34) to hold are that

$$
\frac{1-\beta}{\beta} \Phi \leq 1
$$

and

$$
2 \rho \geq 1+a_{2}\left[\frac{2(1-\rho)}{a_{1}}\right]^{2}\left[\frac{a_{2} \tilde{R}_{2}}{\left(a_{1} \tilde{R}_{1}\right)^{2} \beta A}\right]^{\rho / 1-\rho}
$$

${ }^{21} \Phi^{\prime}(\gamma)=0$ will hold if $\eta=1$ (log utility) or $\delta=0$ (unitary savings rate). 
The proof of Proposition 4 appears in the Appendix.

Part (a) of the proposition makes the obvious point that a reduction in transactions costs increases the equilibrium rate of interest. It also obtains the sharper result that the elasticity of the interest rate with respect to a change in $\tilde{R}_{2}$ is bounded above by 0.5 . Part (b) establishes that an increase in $\tilde{R}_{2}$ - and hence a reduction in transactions costs-must reduce the ratio $\sigma^{*} / \gamma^{*}$ if the interest elasticity of savings is not too large. It is then immediate from Proposition 3 that a reduction in transactions costs must increase the volume of secondary capital market activity, again if the interest elasticity of savings is not too great.

Part (c) of the proposition asserts that the equilibrium rate of growth will fall with a reduction in transactions costs [when $\Phi^{\prime}(\gamma)=0$ ] iff a reduction in transactions costs has a large enough effect on the ratio $\sigma^{*} / \gamma^{*}$ and hence on the level of activity in secondary capital markets. In particular, if a reduction in transactions costs shifts a large enough fraction of savings away from the initiation of new capital investment (and only if it does so), the equilibrium rate of growth must fall.

Part (d) of the proposition states conditions under which it is possible (or necessary) for the equilibrium rate of growth to fall with a reduction in transactions costs. Equation (35) asserts that the rate of growth can fall only if $\rho$ is relatively large and/or the savings rate is relatively low. What accounts for the significance of the parameter $\rho$ in this expression? $\rho$ measures the degree of substitutability between capital produced by different technologies in the capital aggregator (1). Large values of $\rho$ indicate a high degree of substitutability. In the $J=2$ case, only the use of technology 2 obligates agents to make use of capital resale markets (i.e., technology 2 is "transactions intensive"). Hence a reduction in transactions costs-ceteris paribus - increases the attractiveness of technology 2 to investors. Investment is transferred from technology 1 to technology 2. But investments in technology 2 are resold, and hence some savings must be transferred away from the initiation of new capital investment and toward the purchase of claims to existing CIP. The strength of this effect determines whether the equilibrium rate of growth rises or falls with a reduction in transactions costs. The effect is strongest, of course, when there is a high degree of substitutability between the two kinds of capital production technologies or, that is, when $\rho$ is relatively large. And the higher is the savings rate or labor's share, the larger $\rho$ must be in order for declining transactions costs to reduce the rate of growth. ${ }^{22}$

Equations (36) and (37) give conditions under which a reduction in transactions costs will necessarily reduce the rate of growth. As is apparent from Equation (A.14) in the Appendix, reductions in transactions costs are most likely to be growth-reducing when the ratio $\sigma^{*} / \gamma^{*}$ is low. As indicated by Proposition 2, Equation (36) guarantees that $\sigma^{*} / \gamma^{*}<1$ holds. And Equation (37) must be satisfied when $\rho$ is sufficiently near one or, in other words, when there is a high enough degree of substitutability between capital produced using the two alternative investment technologies.

\footnotetext{
${ }^{22}$ Clearly, if $\Phi^{\prime}(\gamma)>0$ holds, this allows some of the additional investment in the purchase of CIP to be financed out of the savings created when the interest rate rises. This will tend to attenuate some of the adverse effects on the growth rate resulting from a reduction in transactions costs.
} 
When $\Phi^{\prime}(\gamma)=0$ holds, Equations (30) and (34) provide an empirical criterion for determining whether or not a reduction in transactions costs will be growth-enhancing. More specifically, it is apparent from Equation (30) that

$$
-\left[\tilde{R}_{2} /\left(\sigma^{*} / \gamma^{*}\right)\right]\left[\partial\left(\sigma^{*} / \gamma^{*}\right) / \partial \tilde{R}_{2}\right]
$$

is the elasticity of the volume of secondary capital market activity with respect to a change in transactions costs when $\Phi^{\prime}(\gamma)=0$. A reduction in transactions costs will raise the rate of growth iff this elasticity is small relative to the elasticity of the interest rate with respect to a change in transactions costs. Since there are typically good empirical proxies for transactions costs - such as bid/ask spreads - and good measures of safe rates of returns and transactions volumes, it is a relatively straightforward matter to think about estimating both elasticities. Thus our results provide a basis for an empirical determination of whether or not transactions cost reductions are likely to be conducive to growth. In view of the fact that attempts to reduce the costs of transacting in financial markets have experienced mixed success in a number of developing countries, ${ }^{23}$ the existence of such a criterion has some practical importance.

5.3. Taxing or Subsidizing Transactions. The fact that a reduction in transactions costs may have adverse consequences for growth raises the following question. Can there be a case on welfare grounds for taxing transactions ${ }^{24}$ in secondary capital markets? We now state conditions under which a tax on these transactions reduces the net-of-tax rate of return $\gamma^{*}$ as well as the equilibrium rate of growth $\sigma^{*}$. The former consequence of a transactions tax lowers the welfare of all generations (since all our agents save when young). The second consequence lowers the utility of all generations after the first. Thus, when our conditions are satisfied, a tax on transactions in secondary capital markets is clearly undesirable from the perspective of economic welfare.

Interestingly, a tax on transactions can lower the real rate of economic growth even when $\partial \sigma / \partial \tilde{R}_{2}<0$ holds. Thus the possibility that lower transactions costs can be growth-reducing need not imply that a tax on financial transactions is growthenhancing.

We introduce taxes on transactions in capital resale markets in the following way: We assume that all sellers of CIP pay a constant proportional tax $\tau$ on the gross proceeds of these sales. ${ }^{25}$ No tax is paid on the rental of mature capital or on the initiation of new capital investments. ${ }^{26}$ Finally, the government uses the proceeds of these taxes to fund expenditures that either do not affect agents' utility, or that affect it in an additively separable way. ${ }^{27}$

${ }^{23}$ See, for instance, Taylor (1980), van Wijnbergen (1983, 1985), and Diaz-Alejandro (1985).

${ }^{24}$ Such taxes on transactions have been widely advocated by James Tobin. See, for instance, Tobin et al. (1995).

${ }^{25}$ Of course, it does not matter to allocations whether buyers or sellers of CIP bear this tax.

${ }^{26}$ These assumptions mirror our assumptions on transactions costs.

${ }^{27}$ If the government rebates the proceeds of transactions taxes to agents, it will generally matter how they are rebated. Rebates via lump-sum transfers to old agents will strengthen the results we obtain here. 
Under these assumptions, our equilibrium conditions must be modified as follows. First, Equation (9) must be replaced with

$$
\left(1-\alpha^{j, h+1}\right)\left(1-\tau^{j, h+1}\right) \frac{P_{t+1}^{j, h+1}}{P_{t}^{j, h}}=\left(1-\alpha^{l, m+1}\right)\left(1-\tau^{l, m+1}\right) \frac{P_{t+1}^{l, m+1}}{P_{t}^{l, m}}
$$

for all $h \leq j-1$, for all $m \leq l-1$, and for all values $j$ and $l$, where $\tau^{j, h}=\tau$ if $h \neq 0$, $j$ and $\tau^{j, 0}=\tau^{j, j}=0$ for all $j$. Second, Equation (10) must be replaced with

$$
\gamma=\left(1-\alpha^{j, h+1}\right)\left(1-\tau^{j, h+1}\right) \frac{P_{t+1}^{j, h+1}}{P_{t}^{j, h}}
$$

where $\gamma$ is now the after-tax real return on savings. Finally, Equations (14) and (15) must be replaced by

$$
r_{j t}=\frac{(\gamma)^{j}}{\tilde{R}_{j} \prod_{h=0}^{j-1}\left(1-\tau^{j, h+1}\right)}
$$

and

$$
k_{j t}=k_{t}\left[\frac{a_{j} \tilde{R}_{j} \beta A \prod_{h=0}^{j-1}\left(1-\tau^{j, h+1}\right)}{(\gamma)^{j}}\right]^{1 / 1-\rho}
$$

for all $j=1, \ldots, J$.

It follows from these modifications that the two equilibrium conditions, [Equations (16) and (29)] now take the form

$$
\sum_{j=1}^{J} a_{j}\left[\frac{a_{j} \tilde{R}_{j} \beta A(1-\tau)^{j}}{(\gamma)^{j}}\right]^{\rho / 1-\rho}=(1-\tau)^{\rho / 1-\rho}
$$

and

$$
\begin{aligned}
\Phi(\gamma) & \frac{(1-\beta)}{\beta}(1-\tau)^{1 / 1-\rho} \\
& =\sum_{j=1}^{J} a_{j}\left[\frac{a_{j} \tilde{R}_{j} \beta A(1-\tau)^{j}}{(\gamma)^{j}}\right]^{\rho / 1-\rho} H_{j}\left[\frac{\gamma}{\sigma(1-\tau)}\right]
\end{aligned}
$$

Clearly, the determination of equilibrium remains recursive: Equation (16") uniquely determines $\gamma^{*}$, and given $\gamma^{*}$, Equation (29') uniquely determines the equilibrium growth rate $\sigma^{*}$. We now turn our attention to how $\gamma^{*}$ and $\sigma^{*}$ are affected by changes in the transactions tax $\tau$. 
PROPOSITION 5. $\partial \gamma^{*} / \partial \tau<0$ holds.

Proposition 5 is proved in the Appendix. The proposition asserts that higher transactions taxes reduce the after-tax rate of return on savings, just as higher transactions costs do.

As before, the effects of changes in $\tau$ on $\sigma^{*}$ are-in general-ambiguous. To sharpen our results, therefore, we henceforth focus on the case $J=2$, and we assume that $\Phi^{\prime}(\gamma)=0$. In addition, we confine our attention to "small" taxes on transactions. Under these conditions, we have the following result:

Proposition 6. Suppose that $J=2$ and $\Phi^{\prime}(\gamma)=0$. Then $\partial \sigma^{*} /\left.\partial \tau\right|_{\tau=0}<0$ holds if $1-\rho \geq \Phi(1-\beta) / \beta$.

The proof of Proposition 6 appears in the Appendix.

Notice that there is a distinctly nontrivial set of parameter values that satisfies $1-\rho \geq \Phi(1-\beta) / \beta$ along with conditions (36) and (37). For all such parameters, increases in $\tilde{R}_{2}$ will lead to a lower rate of equilibrium growth, at least along a balanced growth path. At the same time, the introduction of (small) transactions taxes also will lead to a lower rate of real growth. Thus, as noted previously, when higher transactions costs are conducive to higher rates of growth, this by no means implies that transactions taxes-or policies that are equivalent to transactions taxes - are also conducive to higher rates of growth. Moreover, given our results concerning the sign of $\partial \gamma^{*} / \partial \tau$, it is clear that the content of Proposition 6 can only be strengthened by allowing for $\Phi^{\prime}(\gamma)>0$.

What accounts for the possibility that $\partial \sigma^{*} / \partial \tilde{R}_{2}<0$ may hold at the same time as $\partial \sigma^{*} /\left.\partial \tau\right|_{\tau=0}<0$ ? An increase in the tax on secondary capital market transactions is not equivalent to a reduction in $\tilde{R}_{2}$ because it has no effect on the net productivity of technology 2. As a result, an increase in the tax rate on financial transactions can cause a shift in portfolio composition that causes more investment to be done via an "inferior" technology. This distortion is not conducive to growth, even though it may lower the volume of transactions in capital resale markets. Thus transactions taxes can easily have adverse implications both for real rates of growth and for welfare along a balanced growth path, even when $\partial \sigma^{*} / \partial \tilde{R}_{2}<0$ holds.

\section{THE TERM STRUCTURE}

In order to consider how changes in transactions costs affect the term structure of gross asset yields, it is most interesting to return to the general case $J \geq 2$. In doing so, it is necessary to have a convenient parameterization of transactions costs. We therefore proceed as follows. Let

$$
\tilde{R}_{j}=\tilde{R}_{j}(z) \quad j=1, \ldots, J
$$

so that $z$ is a scalar parameter that governs the level of transactions costs. To be concrete, we let increases in $z$ induce reductions in transactions costs. Thus $\tilde{R}_{j}^{\prime}(z)>0$ holds, for all $j>1$. Since no transactions costs are incurred on one-period projects, we impose that $\tilde{R}_{1}^{\prime}(z)=0$. 
Now let $\lambda_{j}(z)$ denote the gross yield to maturity on investments in new type $j$ capital, where we have made the dependence of this term on the transactions cost parameter explicit. As we have observed previously, $\lambda_{j}(z)$ is given by

$$
\lambda_{j}(z)=\gamma(z)\left[\frac{R_{j}}{\tilde{R}_{j}(z)}\right]^{1 / j} \quad j=1, \ldots, J
$$

where $\gamma(z)$ is the equilibrium rate of return on savings as a function of $z$. Obviously, $\gamma^{\prime}(z)>0$ holds.

The effect of a change in transactions costs on the various yields to maturity is given by the expression

$$
\frac{z \lambda_{j}^{\prime}(z)}{\lambda_{j}(z)}=\frac{z \gamma^{\prime}(z)}{\gamma(z)}-\frac{z \tilde{R}_{j}^{\prime}(z)}{j \tilde{R}_{j}(z)} \quad j=1, \ldots, J
$$

Evidently, the "increase" in $\lambda_{j+1}(z)$ is smaller than the "increase" in $\lambda_{j}(z)$ iff

$$
\frac{\tilde{R}_{j+1}^{\prime}(z)}{(j+1) \tilde{R}_{j+1}(z)}>\frac{\tilde{R}_{j}^{\prime}(z)}{j \tilde{R}_{j}(z)}
$$

When Equation (41) holds for all $j,{ }^{28}$ the effect of a reduction in transactions costs is to increase $\lambda_{1}(z)$. For $j \geq 2, \lambda_{j}(z)$ may either increase or decrease with an increase in $z$. However, in any event, the "increase" in $\lambda_{j+1}(z)$ is smaller than the "increase" in $\lambda_{j}(z)$. Hence, if Equation (41) holds for all $j$, the effect of a reduction in transactions costs is to increase the "short end" of the term structure by more than the "long end." In other words, a reduction in transactions costs flattens the term structure. This result, of course, is reversed whenever Equation (41) fails for some values of $j$.

When Equation (41) holds for all $j$, a flatter term structure is a signal of lower transactions costs. Thus a flatter term structure (cross-sectionally) should be associated with higher real returns - at the "short end" of the term structure. And of course, the relationship between the slope of the term structure and the equilibrium rate of growth depends on the kinds of factors discussed in Section 5.

\section{CONCLUSIONS}

We have considered an economy where the financial sector mediates two conflicting claims on capital: Long-lived capital may be highly productive, but wealth holders may wish to receive the return on their assets over a short horizon. Secondary capital markets accommodate these claims by allowing capital to be owned by a succession of investors. However, these markets also use resources and extract rents. The implied costs of transacting in secondary capital markets influence

\footnotetext{
${ }^{28}$ Equation (41) holds for some obvious transactions cost structures. For instance, if $\alpha^{j, h}=z$ for all $j$, for all $h \neq 0, j$ (and $\alpha^{j, 0}=\alpha^{j, j}=0$ ), then $\tilde{R}_{j}(z)=R_{j}(1-z)^{j-1}$, for all $j$. It is then easy to verify that Equation (41) is satisfied for all $j$.
} 
an economy's equilibrium return on savings, the equilibrium rate of growth, the volume of financial market activity, and the term structure (gross of transactions costs) of asset yields.

Reductions in the costs of transacting in secondary capital markets raise the return to savings (the "short end" of the term structure) and, under weak conditions, reduce the yield on the "long end" of the term structure. This increases the attractiveness of long-gestation investments (ceteris paribus), which also tends (again, ceteris paribus) to increase the volume of secondary capital market activity. This reduction in transactions costs has complicated implications, however, for the equilibrium growth rate of an economy. These implications depend critically on the degree of substitutability between short- and long-lived capital as inputs in the production process, since it is exactly this factor which determines how much savings is diverted away from the initiation of new investment - and into secondary capital markets - by a reduction in the costs of transacting. This observation permits us to provide some insights into conditions under which financial deepening will and will not be conducive to growth.

We conclude by offering some comments on the general issue of model specification. By analyzing an economy with long-gestation investments and two-period lived agents, we essentially have forced agents to transact in secondary capital markets. And our focus has been on what happens as the costs of participating in these markets change. We have particularly emphasized the consequences of changes in transactions costs for long-run capital formation and long-run growth.

There are, of course, other devices that could be used for forcing agents to participate in secondary capital markets. For example, Aiyagari and Gertler (1991) generate activity in secondary asset markets by assuming that long-lived agents hold assets of varying maturities, that these agents are subject to idiosyncratic risk, that markets for insuring this risk are absent, and that borrowing/lending is sufficiently costly. Clearly, we could introduce some or all of these features into our analysis. Of course, Aiyagari and Gertler consider a pure exchange economy with a very pronounced market incompleteness. We consider a production economy with complete markets and analyze the consequences for long-run growth of resources being expended in these markets. It is not clear that it would be straightforward to analyze this issue using the Aiyagari-Gertler model. But, in any event, a hybrid of our model and theirs would yield a more interesting theory than ours of the relative demands for assets of different maturities. Such an investigation would be an interesting topic for future research.

\section{APPENDIX}

Proof of Lemma 1. Parts (a), (c), and (d) are straightforward. For part (b), observe that

(A.1) $\quad H_{j+1}(x)=\frac{x^{j+1}-1}{x^{j+1}(x-1)}=\frac{1}{x} \cdot\left[\frac{x^{j}-1}{x^{j}(x-1)}+1\right]=x^{-1}\left[H_{j}(x)+1\right]$ 
Now suppose, for the purpose of a proof by contradiction, that $H_{j+1}(x)<H_{j}(x)$ for some $x$. Then, by Equation (A.1), $H_{j}(x)+1 \leq x H_{j}(x)$ or $1 \leq(x-1) H_{j}(x)=\left(x^{j}-\right.$ 1) $/ x^{j}$. This is the desired contradiction. Moreover, evidently $H_{j+1}(x)>H_{j}(x)$ holds for all $x<\infty$.

For part (e), straightforward differentiation yields

$$
\frac{H_{j}^{\prime}(x)}{H_{j}(x)}=\frac{-x^{j+1}+(j+1) x-j}{\left(x^{j}-1\right)(x-1) x}
$$

Now define, for $j=1, \ldots, J$,

$$
\eta_{j}(x) \equiv-x^{j+1}+(j+1) x-j
$$

Evidently $\eta_{j}(1)=0$ holds, for all $j$, and

$$
\eta_{j}^{\prime}(x)=(j+1)\left(1-x^{j}\right)
$$

Therefore, $\eta_{j}^{\prime}>(<) 0$ for all $x<(>) 1$ holds. If follows that $\eta_{j}(x)<\eta_{j}(1)=0$, for all $x \neq 1$. Thus, from Equation (A.2), $H_{j}^{\prime}(x)<0$ for all $x \neq 1$. That $H_{j}^{\prime}(1)<0$ follows from repeated applications of L'Hôpital's rule to Equation (A.2).

Proof of Proposition 1. It is immediate from an inspection of Equation (16) that there exists a unique value $\gamma^{*}$ satisfying that condition. Then $\sigma^{*}$ must satisfy

$$
\Phi\left(\gamma^{*}\right) \frac{1-\beta}{\beta}=\sum_{j} a_{j}\left[\frac{a_{j} \tilde{R}_{j} \beta A}{\left(\gamma^{*}\right)^{j}}\right]^{\rho / 1-\rho} H_{j}\left(\frac{\gamma^{*}}{\sigma}\right)
$$

The existence of a solution to Equation (A.4) follows from parts (c) and (d) of Lemma 1. That that solution is unique follows from part (e) of the same lemma.

Proof of Proposition 2. The proof is by contradiction. Suppose to the contrary that $\gamma^{*} / \sigma^{*} \leq 1$ holds. Then, since $H_{j}^{\prime}<0$, Equation (29) implies that

$$
\begin{aligned}
1 & \geq \Phi\left(\gamma^{*}\right) \frac{1-\beta}{\beta} \geq \sum_{j} a_{j}\left[\frac{a_{j} \tilde{R}_{j} \beta A}{\left(\gamma^{*}\right)^{j}}\right]^{\rho / 1-\rho} H_{j}(1) \\
& =\sum_{j} j a_{j}\left[\frac{a_{j} \tilde{R}_{j} \beta A}{\left(\gamma^{*}\right)^{j}}\right]^{\rho / 1-\rho}
\end{aligned}
$$

where the second equality follows from L'Hôpital's rule. But Equation (A.5) clearly contradicts Equation (16), establishing the proposition. 
Proof of Proposition 3. It follows from Equation (27) that

$$
\begin{aligned}
& \Phi\left(\gamma^{*}\right)\left(\frac{1-\beta}{\beta}\right)\left(1-\sum_{j} \theta^{j, 0}\right) \\
& =\Phi\left(\gamma^{*}\right)\left(\frac{1-\beta}{\beta}\right)-\sum_{j} a_{j}\left[\frac{a_{j} \tilde{R}_{j} \beta A}{\left(\gamma^{*}\right)^{j}}\right]^{\rho / 1-\rho}\left(\frac{\sigma^{*}}{\gamma^{*}}\right)^{j} \\
& =\sum_{j} a_{j}\left[\frac{a_{j} \tilde{R}_{j} \beta A}{\left(\gamma^{*}\right)^{j}}\right]^{\rho / 1-\rho}\left(\frac{\sigma^{*}}{\gamma^{*}}\right)^{j}\left\{\frac{\left(\frac{\gamma^{*}}{\sigma^{*}}\right)^{j}-\left(\frac{\gamma^{*}}{\sigma^{*}}\right)}{\left(\frac{\gamma^{*}}{\sigma^{*}}\right)-1}\right\}
\end{aligned}
$$

where the second equality follows from Equation (29) and the definition of $H_{j}\left(\gamma^{*} / \sigma^{*}\right)$. We now observe that Equation (A.6) can be rewritten as

$$
\text { (A.7) } \begin{aligned}
\Phi\left(\gamma^{*}\right) & \left(\frac{1-\beta}{\beta}\right)\left(1-\sum_{j} \theta^{j, 0}\right) \\
& =\sum_{j} a_{j}\left[\frac{a_{j} \tilde{R}_{j} \beta A}{\left(\gamma^{*}\right)^{j}}\right]^{\rho / 1-\rho} H_{j-1}\left(\frac{\gamma^{*}}{\sigma^{*}}\right) \\
& =\left(\frac{\gamma^{*}}{\sigma^{*}}\right) \sum_{j} a_{j}\left[\frac{a_{j} \tilde{R}_{j} \beta A}{\left(\gamma^{*}\right)^{j}}\right]^{\rho / 1-\rho} H_{j}\left(\frac{\gamma^{*}}{\sigma^{*}}\right)-\sum_{j} a_{j}\left[\frac{a_{j} \tilde{R}_{j} \beta A}{\left(\gamma^{*}\right)^{j}}\right]^{\rho / 1-\rho} \\
& =\left(\frac{\gamma^{*}}{\sigma^{*}}\right) \Phi\left(\gamma^{*}\right)\left(\frac{1-\beta}{\beta}\right)-1
\end{aligned}
$$

where the second equality follows from Equation (A.1) and the third follows from Equations (16) and (29). Rearranging terms in Equation (A.7) now yields Equation (30).

Proof of Proposition 4. (a) Differentiating equation (31) with respect to $\tilde{R}_{2}$ yields

(A.8) $a_{2}\left[\frac{a_{2} \tilde{R}_{2} \beta A}{\left(\gamma^{*}\right)^{2}}\right]^{\rho / 1-\rho}$

$$
\begin{aligned}
& =\left(\frac{\tilde{R}_{2}}{\gamma^{*}}\right) \frac{\partial \gamma^{*}}{\partial \tilde{R}_{2}}\left\{a_{1}\left(\frac{a_{1} \tilde{R}_{1} \beta A}{\gamma^{*}}\right)^{\rho / 1-\rho}+2 a_{2}\left[\frac{a_{2} \tilde{R}_{2} \beta A}{\left(\gamma^{*}\right)^{2}}\right]^{\rho / 1-\rho}\right\} \\
& =\left(\frac{\tilde{R}_{2}}{\gamma^{*}}\right) \frac{\partial \gamma^{*}}{\partial \tilde{R}_{2}}\left\{a_{1}\left(\frac{a_{1} \tilde{R}_{1} \beta A}{\gamma^{*}}\right)^{\rho / 1-\rho}\right.
\end{aligned}
$$




$$
\begin{gathered}
\left.+a_{2}\left[\frac{a_{2} \tilde{R}_{2} \beta A}{\left(\gamma^{*}\right)^{2}}\right]^{\rho / 1-\rho}+a_{2}\left[\frac{a_{2} \tilde{R}_{2} \beta A}{\left(\gamma^{*}\right)^{2}}\right]^{\rho / 1-\rho}\right\} \\
=\left(\frac{\tilde{R}_{2}}{\gamma^{*}}\right) \frac{\partial \gamma^{*}}{\partial \tilde{R}_{2}}\left\{1+a_{2}\left[\frac{a_{2} \tilde{R}_{2} \beta A}{\left(\gamma^{*}\right)^{2}}\right]^{\rho / 1-\rho}\right\}
\end{gathered}
$$

where the last equality follows from Equation (31). The first equality in Equation (33) is then immediate. Moreover, Equation (31) implies that

$$
a_{2}\left[\frac{a_{2} \tilde{R}_{2} \beta A}{\left(\gamma^{*}\right)^{2}}\right]^{\rho / 1-\rho}<1
$$

is satisfied. This implies the inequality in Equation (33).

(b) Differentiating Equation (32) with respect to $\tilde{R}_{2}$ and imposing $\Phi^{\prime}(\gamma)=0$, we obtain

$$
\begin{aligned}
& \left(\frac{\rho}{\rho-1}\right) a_{2}\left[\frac{a_{2} \tilde{R}_{2} \beta A}{\left(\gamma^{*}\right)^{2}}\right]^{\rho / 1-\rho}\left[1-2\left(\frac{\tilde{R}_{2}}{\gamma^{*}}\right) \frac{\partial \gamma^{*}}{\partial \tilde{R}_{2}}\right] \\
& \quad=\left(\frac{\tilde{R}_{2}}{\sigma^{*} / \gamma^{*}}\right) \frac{\partial\left(\sigma^{*} / \gamma^{*}\right)}{\partial \tilde{R}_{2}}\left\{\frac{\sigma^{*}}{\gamma^{*}}+2 a_{2}\left[\frac{a_{2} \tilde{R}_{2} \beta A}{\left(\gamma^{*}\right)^{2}}\right]^{\rho / 1-\rho}\left(\frac{\sigma^{*}}{\gamma^{*}}\right)^{2}\right\}
\end{aligned}
$$

The claim then follows immediately from $\left(\tilde{R}_{2} / \gamma^{*}\right) \partial \gamma^{*} / \partial \tilde{R}_{2}<0.5$.

(c) Clearly,

$$
\left(\frac{\tilde{R}_{2}}{\sigma^{*}}\right) \frac{\partial \sigma^{*}}{\partial \tilde{R}_{2}}=\left(\frac{\tilde{R}_{2}}{\sigma^{*} / \gamma^{*}}\right) \frac{\partial\left(\sigma^{*} / \gamma^{*}\right)}{\partial \tilde{R}_{2}}+\left(\frac{\tilde{R}_{2}}{\gamma^{*}}\right) \frac{\partial \gamma^{*}}{\partial \tilde{R}_{2}}
$$

The claim follows directly from Equation (A.10).

(d) We first use Equation (32) to rewrite Equation (A.9) as

$$
\begin{aligned}
\left(\frac{\tilde{R}_{2}}{\sigma^{*} / \gamma^{*}}\right) \frac{\partial\left(\sigma^{*} / \gamma^{*}\right)}{\partial \tilde{R}_{2}}= & \left(\frac{\rho}{\rho-1}\right) a_{2}\left[\frac{\dot{a}_{2} \tilde{R}_{2} \beta A}{\left(\gamma^{*}\right)^{2}}\right]^{\rho / \rho-1} \\
& \times \frac{\left[1-2\left(\frac{\tilde{R}_{2}}{\gamma^{*}}\right) \frac{\partial \gamma^{*}}{\partial \tilde{R}_{2}}\right]}{\left\{\Phi \frac{1-\beta}{\beta}+a_{2}\left[\frac{a_{2} \tilde{R}_{2} \beta A}{\left(\gamma^{*}\right)^{2}}\right]^{\rho / 1-\rho}\left(\frac{\sigma^{*}}{\gamma^{*}}\right)^{2}\right\}}
\end{aligned}
$$


Equations (33) and (A.11) imply that Equation (34) is satisfied iff (A.12)

$$
\frac{\left(\frac{\rho}{1-\rho}\right)\left[1-2\left(\frac{\tilde{R}_{2}}{\gamma^{*}}\right) \frac{\partial \gamma^{*}}{\partial \tilde{R}_{2}}\right]}{\left\{\Phi \frac{1-\beta}{\beta}+a_{2}\left[\frac{a_{2} \tilde{R}_{2} \beta A}{\left(\gamma^{*}\right)^{2}}\right]^{\rho / 1-\rho}\left(\frac{\sigma^{*}}{\gamma^{*}}\right)^{2}\right\}} \geq \frac{1}{\left\{1+a_{2}\left[\frac{a_{2} \tilde{R}_{2} \beta A}{\left(\gamma^{*}\right)^{2}}\right]^{\rho / 1-\rho}\right\}}
$$

Obviously, a set of sufficient conditions for Equation (A.12) to hold is that Equation (36), $\sigma^{*} / \gamma^{*} \leq 1$, and

$$
\left(\frac{\rho}{1-\rho}\right)\left[1-2\left(\frac{\tilde{R}_{2}}{\gamma^{*}}\right) \frac{\partial \gamma^{*}}{\partial \tilde{R}_{2}}\right] \geq 1
$$

hold, with at least one inequality strict. But Proposition 2 asserts that Equation (36) is sufficient for $\sigma^{*} / \gamma^{*}<1$ to hold. Thus Equations (36) and (A.13) are sufficient for Equation (34) to hold.

Substituting Equation (33) into Equation (A.13) and rearranging terms, it is straightforward to show that Equation (A.13) is equivalent to

$$
\gamma^{*} \leq\left(a_{1} \tilde{R}_{1} \beta A\right)\left[\frac{a_{1}}{2(1-\rho)}\right]^{(1-\rho) / \rho}
$$

It is also straightforward to verify from Equation (31) that Equation (A.13') holds iff Equation (37) is satisfied. Thus Equations (36) and (37) are sufficient for Equation (34), as claimed.

To establish the remainder of part (d), substitute Equation (33) into Equation (A.12). On rearranging terms, the result is that Equation (34) is satisfied iff

$$
\left(\frac{\rho}{1-\rho}\right)\left\{1-a_{2}\left[\frac{a_{2} \tilde{R}_{2} \beta A}{\left(\gamma^{*}\right)^{2}}\right]^{\rho / 1-\rho}\right\}>\Phi \frac{1-\beta}{\beta}+\left(\frac{\sigma^{*}}{\gamma^{*}}\right)^{2} a_{2}\left[\frac{a_{2} \tilde{R}_{2} \beta A}{\left(\gamma^{*}\right)^{2}}\right]^{\rho / 1-\rho}
$$

holds. Obviously, a necessary condition for Equation (A.14) to hold is that Equation (35) be satisfied. This completes the proof.

Proof of Proposition 5. Differentiating Equation (16") with respect to $\tau$, we obtain

$$
\begin{aligned}
\gamma^{*}(1 & -\tau)^{\rho / 1-\rho}-\gamma^{*} \sum_{j=1}^{J} j a_{j}\left[\frac{a_{j} \tilde{R}_{j} \beta A(1-\tau)^{j}}{\left(\gamma^{*}\right)^{j}}\right]^{\rho / 1-\rho} \\
& =(1-\tau)\left\{\sum_{j=1}^{J} j a_{j}\left[\frac{a_{j} \tilde{R}_{j} \beta A(1-\tau)^{j}}{\left(\gamma^{*}\right)^{j}}\right]^{\rho / 1-\rho}\right\} \frac{\partial \gamma^{*}}{\partial \tau}
\end{aligned}
$$


798

BENCIVENGA, SMITH, STARR

Moreover,

$$
\sum_{j=1}^{J} j a_{j}\left[\frac{a_{j} \tilde{R}_{j} \beta A(1-\tau)^{j}}{\left(\gamma^{*}\right)^{j}}\right]^{\rho / 1-\rho}>\sum_{j=1}^{J} a_{j}\left[\frac{a_{j} \tilde{R}_{j} \beta A(1-\tau)^{j}}{\left(\gamma^{*}\right)^{j}}\right]^{\rho / 1-\rho}=(1-\tau)^{\rho / 1-\rho}
$$

where the second equality follows from Equation (16"). Thus $\partial \gamma^{*} / \partial \tau<0$.

Proof of Proposition 6. When $J=2$ and $\Phi(\gamma)=\Phi$ hold, Equation (16") reduces to

(A.15)

$$
\begin{aligned}
\gamma^{\rho / 1-\rho}= & \left(\frac{a_{1}}{2}\right)\left(a_{1} \tilde{R}_{1} \beta A\right)^{\rho / 1-\rho} \\
& +\left\{\left(\frac{a_{1}}{2}\right)^{2}\left(a_{1} \tilde{R}_{1} \beta A\right)^{2 \rho / 1-\rho}+a_{2}\left[a_{2} \tilde{R}_{2} \beta A(1-\tau)\right]^{\rho / 1-\rho}\right\}^{1 / 2}
\end{aligned}
$$

Also, Equation $\left(29^{\prime}\right)$ can be written as

$$
\Phi \frac{1-\beta}{\beta}=\frac{\sigma}{\gamma}+(1-\tau)\left(\frac{\sigma}{\gamma}\right)^{2}\left[1-a_{1}\left(\frac{a_{1} \tilde{R}_{1} \beta A}{\gamma}\right)^{\rho / 1-\rho}\right]
$$

From Equation (A.15) it follows that

$$
\left(\frac{1-\tau}{\gamma}\right) \frac{\partial \gamma}{\partial(1-\tau)}=\frac{1-a_{1}\left(\frac{a_{1} \tilde{R}_{1} \beta A}{\gamma}\right)^{\rho / 1-\rho}}{2\left[1-\left(\frac{a_{1}}{2}\right)\left(\frac{a_{1} \tilde{R}_{1} \beta A}{\gamma}\right)^{\rho / 1-\rho}\right]}<0.5
$$

From Equation (A.16) we have

$$
\begin{aligned}
& \left(\frac{1-\tau}{\sigma}\right) \frac{\partial \sigma}{\partial(1-\tau)}=\left(\frac{1-\tau}{\gamma}\right) \frac{\partial \gamma}{\partial(1-\tau)} \\
& -\frac{(1-\tau)\left[1-a_{1}\left(\frac{a_{1} \tilde{R}_{1} \beta A}{\gamma}\right)^{\rho / 1-\rho}+\left(\frac{\rho}{1-\rho}\right) a_{1}\left(\frac{a_{1} \tilde{R}_{1} \beta A}{\gamma}\right)^{\rho / 1-\rho}\left(\frac{1-\tau}{\gamma}\right) \frac{\partial \gamma}{\partial(1-\tau)}\right]}{\frac{\gamma}{\sigma}+2(1-\tau)\left[1-a_{1}\left(\frac{a_{1} \tilde{R}_{1} \beta A}{\gamma}\right)^{\rho / 1-\rho}\right]}
\end{aligned}
$$


Equations (A.17) and (A.18) imply that $\partial \sigma / \partial(1-\tau) \geq 0[\partial \sigma / \partial \tau \leq 0]$ holds iff

$$
\frac{\gamma}{\sigma} \geq 2 \tau+a_{1}\left(\frac{a_{1} \tilde{R}_{1} \beta A}{\gamma}\right)^{\rho / 1-\rho}\left(\frac{1}{1-\rho}-2 \tau\right)
$$

is satisfied. Evaluating Equation (A.19) at $\tau=0$, we have that

$$
\left.\frac{\partial \sigma}{\partial(1-\tau)}\right|_{\tau=0} \geq 0
$$

holds iff

$$
\frac{\gamma}{\sigma} \geq \frac{a_{1}\left(\frac{a_{1} \tilde{R}_{1} \beta A}{\gamma}\right)^{\rho / 1-\rho}}{1-\rho}
$$

obtains. But Equation (A.15) implies that

$$
1>a_{1}\left(\frac{a_{1} \tilde{R}_{1} \beta A}{\gamma}\right)^{\rho / 1-\rho}
$$

and Equation (A.16) implies that

$$
\frac{\gamma}{\sigma}>\frac{\beta}{\Phi(1-\beta)}
$$

Thus $\partial \sigma /\left.\partial(1-\tau)\right|_{\tau=0} \geq 0$ must hold if $1-\rho \geq \Phi[(1-\beta) / \beta]$, as claimed.

\section{REFERENCES}

Aiyagari, S. Rao, and Mark Gertler, "Asset Returns with Transactions Costs and Uninsured Individual Risk," Journal of Monetary Economics 27 (1991), 311-31.

$\rightarrow$ Bencivenga, Valerie R., and Bruce D. Smith, "Financial Intermediation and Endogenous Growth," Review of Economic Studies 58 (1991), 195-209.

, - - AND Ross M. STARr, "Liquidity of Secondary Capital Markets, Capital Accumulation, and the Term Structure of Asset Yields," manuscript, University of Texas at Austin, 1994.

,-- , AND —— "Transactions Costs, Technological Choice, and Endogenous Growth," Journal of Economic Theory 67 (1995), 153-77.

,-- AND —— "Liquidity of Secondary Capital Markets: Allocative Efficiency and the Maturity Composition of the Capital Stock," Economic Theory 7 (1996), 19-50.

Bohm-Bawerk, E. von, Positive Theory of Capital, trans. by W. Smart (London: Macmillan, 1891).

Buffie, Edward F., "Financial Repression, the New Structuralists, and Stabilization Policy in Semi-industrialized Economies," Joumal of Development Economics 14 (1984), 305-22.

$\rightarrow$ Diamond, Peter A., "National Debt in a Neoclassical Growth Model," American Economic Review 55 (1965), 1126-50.

Diaz-Alejandro C., "Good-bye Financial Repression, Hello Financial Crash," Joumal of Development Economics 19 (1985), 1-24.

$\rightarrow$ Eichengreen, Barry, James Tobin, and Charles Wyplosz, "Two Cases for Sand in the Wheels of International Finance," The Economic Joumal (1995), 162-72. 
Fry, MaXwell, Money, Interest, and Banking in Economic Development (Baltimore: Johns Hopkins University Press, 1988).

Greenwood, Jeremy, and Boyan Jovanovic, "Financial Development, Growth, and the Distribution of Income," Joumal of Political Economy 98 (1990), 1076-1107.

— AND BRUCE D. Smith, "Financial Markets in Development, and the Development of Financial Markets," Journal of Economic Dynamics and Control 21 (1997), 145-81.

$\rightarrow$ Gurley, J., AND E. Shaw, "Financial Structure and Economic Development," Economic Development and Cultural Change 15 (1967), 257-68.

Hicks, John, A Theory of Economic History (Oxford, England: Clarendon Press, 1969).

Keynes, John Maynard, The General Theory of Employment, Interest, and Money (New York: Harcourt Brace and World, 1936).

$\rightarrow$ Kydland, Finn, And Edward C. Prescott, "Time to Build and Aggregate Fluctuations" Econometrica 50 (1982), 1345-71.

$\rightarrow$ Levine, Ross, And Sara Zervos, "Stock Markets, Banks, and Economic Growth," American Economic Review 88 (1998), 537-58.

McKinnon, Ronald I., Money and Capital in Economic Development (Washington: Brookings Institution, 1973).

North, Douglas, Institutions, Institutional Change, and Economic Performance (Cambridge, England: Cambridge University Press, 1990).

$\rightarrow$ Romer, PAUL, "Increasing Returns and Long-run Growth," Journal of Political Economy 94 (1986), 1002-37.

Sharpe, William F., Investments (Englewood Cliffs, NJ: Prentice-Hall, 1985).

SHaw, E., Financial Deepening in Economic Development (London: Oxford University Press, 1973).

$\rightarrow$ Shell, Karl, "Toward a Theory of Inventive Activity and Capital Accumulation," American Economic Review (1966), 62-8.

Shen, P., "Essays on Bid-ask Spreads, Term Premia, and Excess Returns," Ph.D. dissertation, University of California, San Diego, 1993.

— AND Ross M. STARR, "Liquidity of the Treasury Bill Market and the Term Structure of Interest Rates," Joumal of Economics and Business 50 (1998), 401-18.

Shiller, Robert J., "The Term Structure of Interest Rates," in B. M. Friedman and F. H. Hahn, eds., Handbook of Monetary Economics (Amsterdam: North Holland, 1990).

Starr, Ross M., "On the Theoretical Foundations of Financial Intermediation and Secondary Capital Markets," Princeton Essays in International Finance 169 (1987), 53-60.

$\rightarrow$ Stoll, H. R., "The Supply of Dealer Services in Securities Markets," Journal of Finance 33 (1978), $1133-52$.

TAYLOR, LANCE, "IS-LM in the Tropics: Diagrammatics of the New Structuralist Critique," in W. R. Cline and S. Weintraub, eds., Economic Stabilization in Developing Countries (Washington: Brookings Institution, 1980).

van Wijnbergen, Sweder, "Stagflationary Effects of Monetary Stabilization Policies: A Quantitative Analysis of South Korea," Journal of Development Economics 10 (1982), 133-69.

—_, "Credit Policy, Inflation, and Growth in a Financially Repressed Economy," Journal of Development Economics 13 (1983), 45-65.

$\longrightarrow$ "Macroeconomic Effects of Changes in Bank Interest Rates: Simulation Results for South Korea," Joumal of Development Economics 18 (1985), 541-54. 